\title{
Misconceptions of the Deaf: Giving voice to the voiceless
}

\author{
D.R. Terry; Q. Lê; H.B. Nguyen; C. Malatzky
}

Vol 9-10 (2016-2017) | ISSN 2161-6590 (online)

DOI 10.5195/hcs.2017.211 | http://hcs.pitt.edu

\section{(cc) $\mathrm{EY}$}

New articles in this journal are licensed under a Creative Commons Attribution 3.0 United States License.

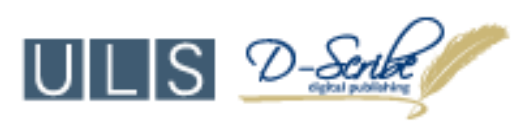

This journal is published by the University Library System of the University of Pittsburgh as part of its $\underline{D}$-Scribe Digital Publishing Program, and is cosponsored by the University of Pittsburgh Press. 
Abstract

The Deaf usually do not see themselves as having a disability; however, discourses and social stereotyping continue to portray the Deaf rather negatively. These discourses may lead to misconceptions, prejudice and possibly discrimination. A study was conducted to identify the challenges members of the Deaf community experience accessing quality health care in a small Island state of Australia. Using a qualitative approach, semi-structured interviews and focus groups were conducted with service providers and the Deaf community. Audist discourses of deafness as deficiency, disability and disease remain dominant in contemporary society and are inconsistency with the Deaf community's own perception of their reality. Despite the dominant constructions of deafness and their affect on the Deaf's experience of health service provision, many Deaf have developed skills, confidence and resilience to live in the hearing world. The Deaf were pushing back on discourses that construct deafness as a disempowering impairment.

Keywords: health; medical; Deaf; misconceptions; assumptions 


\title{
Misconceptions of the Deaf: Giving voice to the voiceless
}

\author{
D.R. Terry; Q. Lê; H.B. Nguyen; C. Malatzky
}

\section{Introduction}

In Australia, those who identify themselves as 'Culturally Deaf' or 'Deaf' are usually those who were born deaf or lost hearing early in life, are pre-lingually deaf and use sign language, such as Auslan, as their primary or preferred mode of communication (Deaf Australia Inc., 2014; Hyde \& Power, 1992). Sign languages like Auslan are independent languages (Napier \& Kidd, 2013). Languages such as English are usually second languages for many Deaf, and English literacy is often poor among the broader Australian Deaf community (Napier \& Kidd, 2013; Nilsson, Turner, Sheikh, \& Dean, 2013). However, it is often assumed that all Deaf people can communicate fluently and comfortably in written English (Batterbury, Ladd, \& Gulliver, 2007; Denman, 2007; Department of Health, 2005; Steinberg, Sullivan, \& Loew, 1998).

Most Deaf are members of a Deaf community; they share a language as well as a myriad of traditions, rituals, social behaviours and histories that have produced many common experiences amongst a group of people (Batterbury et al., 2007; Graybill et al., 2010; Harmer, 1999; Johnston, 2004; Ladd \& Lane, 2013). The Deaf share a distinct culture. However, this reality is not widely understood within the hearing community, nor within most mainstream health services (Steinberg, Barnett, Meador, Wiggins, \& Zazove, 2006).

From the perspective of Deaf culture, deafness is rarely seen as a disability (Lane, 2002). Rather, Deaf people have a different way of communicating and experiencing life than the hearing (Ladd, 2005). Yet most dominant discourses, and the stereotypes they produce, routinely portray the Deaf as disabled (Ladd, 2005; McKee, 2008). These constructions produce further misconceptions, leading to prejudice and sometimes, discriminatory practices (Foss, 2014; McKee, 2008). The social injustice and prejudicial treatment experienced by many of the Deaf in a hearing world (see Barnett et al., 2011; Davidson, Cave, Reedman, Briffa, \& Dark, 2012; Sheppard \& Badger, 2010) is a product of the marginalisation of Deaf culture.

In this article, we draw on empirical data collected in a small Island state of Australia to identify the challenges members of the Deaf community experience accessing quality health care. These challenges are situated within the context of dominant constructions of deafness and Deaf people and how they position the Deaf community in the broader social field. It is argued that these dominant constructions inform many of the popular assumptions about the Deaf, and the way in which the health care needs of the Deaf community are (mis)perceived and in many cases, disregarded within the hearing community. In doing this analysis, our findings highlight the persistence of many inaccurate understandings of the Deaf, and the need for health care services to consider the importance of selfdetermination to equitable health care provision. 


\section{Related Literature}

The fact that the Deaf are a culturally and linguistically distinct group of people with specific cultural and communicative needs is not always recognised or catered for within mainstream health services (Denman, 2007). The assumption that the Deaf are literate in English and the limited health information communicated in Auslan has been identified as key barriers for the Deaf in accessing quality health care (Napier \& Kidd, 2013). Many health service providers have also been found to lack confidence with interpreters, who are not always used when requested (Denman, 2007). Concurrently, there is a lack of funding for interpretive and translation services in Australia (Napier $\&$ Kidd, 2013). Consequently, many Deaf feel culturally insecure in health care settings (Denman, 2007). Most Deaf have fewer opportunities to gain knowledge about the health care system, and health-related information (Napier \& Kidd, 2013; Nilsson et al., 2013) and there is a reported disparity between the quality of health care that the hearing as opposed to the Deaf receives (Denman, 2007; Napier \& Kidd, 2013).

International research points to the importance of interpretative and translation services for the Deaf's access to quality health care (Nilsson et al., 2013). Yet globally, there is a shortage of qualified interpreters (Nilsson et al., 2013). In Australia, many Deaf clients have to rely on family and friends to act as interpreters in medical consultations, despite evidence that the use of informal interpreters increases the chances that Deaf clients will miss important elements of the exchange (Denman, 2007). These communicative barriers can also mean that the client is left out of discussions about their own health care needs and decisions, and that their privacy and confidentiality is compromised in ways that the hearing community do not experience (Denman, 2007). Combined, these factors can result in misunderstandings, misdiagnoses, incorrect treatments and management plans (Denman, 2007; Napier \& Kidd, 2013) and a reluctance on the behalf of the Deaf to access the health care services they need (Nilsson et al., 2013).

\section{Methods}

Critical Discourse Analysis (CDA), with its potential to expose social inequalities and influence social change, is useful for the analysis of dominant discourses which work to position the Deaf in particular ways, and thus, shape the way that the Deaf experience the world around them (Alvesson \& Karreman, 2000; McCloskey, 2008; Moore \& Pollack, 1992). CDA is principally concerned with illustrating how discourse is fashioned by its relationship with power, ideology and the dominance of specific social groups (Dunmire, 2011; Van Dijk, 2001; Wodak, 2002; Wodak \& Meyer, 2009). As such, CDA is used to observe and determine where social power, dominance, and inequality are enacted and reproduced and 'should have effects in society: empowering the powerless, giving voices to the voiceless, exposing power abuse, and mobilizing people to remedy social wrongs' (Blommaert \& Bulcaen, 2000, p. 449).

CDA considers language a social practice where a relationship exists between an event and the situation in which it occurs. Thus the context of language use is vital (Wodak, 2002; Wodak \& Meyer, 2009). As such, discourse establishes:

Situations, objects of knowledge, and the social identities of and relationships between people and groups of people. It [...] helps to sustain and reproduce the social status quo [and] can help produce and reproduce unequal power relations between [...] social classes, women and men, and ethnic/cultural majorities and minorities (Fairclough \& Wodak, 1997, p. 258). 
Discourse, language and text are heavily encoded with ideologies. From a CDA standpoint, the use of speech and hearing within and among societies is a means of verbal communication and a social practice that can marginalise those who are perceived as 'non-native' or non-hearers and non-speakers of the language. This reflects the discourse of social control, meaning making and empowerment (Bodenheimer, Chen, \& Bennett, 2009; Dunmire, 2011; Fairclough, 1992; Van Dijk, 2001, 2003; Wodak, 2002; Wodak \& Meyer, 2009). Thus, researchers need to uncover power relationships and social inequities as they manifest, both structurally and linguistically, towards the Deaf, which are not readily visible to hearing societies.

The research reported on in this article adopted a qualitative approach and used semi-structured interviews and focus groups among the Deaf, and semi-structured interviews with service providers to identify contemporary discourses constructing deafness and examine how they shape the Deaf's experience of health care in Tasmania. This research design gave a voice to the Deaf, allowing them to share their experiences and challenges. The input of some service providers, some of whom were Deaf, also offered a unique insight into the organisational and personal factors which impact the provision of services to the Deaf community.

\section{Setting and participant selection}

This study was conducted in Tasmania, a small island state off the south east coast of mainland Australia with a population of over 500,000 (Australian Bureau of Statistics, 2012). Currently, there are approximately 299 people who report using some form of sign language within Tasmania (Australian Bureau of Statistics, 2012). In relation to the wider Deaf population of Australia $(9,935)$, the Tasmanian Deaf population is small and geographically isolated, factors that are likely to accentuate the challenges they encounter within the hearing community. There are two services that provide Auslan interpreting in Tasmania: the National Auslan Interpreter Booking and Payment Service (NABS), which is funded by the Australian Government to provide free interpretive services for private health care appointments; and the Tasmanian Deaf Society (TasDeaf), who provides and undertakes interpreter services in all other situations.

As part of a wider health program, two groups of participants were invited to be interviewed or participate in a focus group between March and August 2014. The first group comprised members of the Deaf community in Tasmania, who were recruited with the assistance of TasDeaf, who agreed advertise the project through letters, flyers and their bimonthly newsletters. The second group included members of the two Auslan interpreting service providers (both Deaf and hearing) that work in various sites across Tasmania. These participants were approached directly. A formal invitation letter and information sheet was provided to each potential participant. In light of English literacy issues, the information sheet and consent forms were written and assessed at the Flesch-Kincaid score Grade 7.4 and Grade 7.1 level respectively. To verify and validate these documents, consultation with the Deaf community was gained. In addition, additional explanation was provided through an interpreter before or on the day of the official interview or focus group.

\section{Deaf participants}

A sample of 21 self-identifying members of the Deaf Tasmanian community participated in the study. Three of these participants directly approached researchers; snowballing or direct contact through TasDeaf was employed to recruit the remaining participants. A focus group was conducted with 10 participants, who were a group of Deaf who met regularly, while the remaining 11 were interviewed. The aim of these interviews and focus groups was to gain an in-depth understanding of how the Deaf community experience health care in Tasmania.

\section{Service providers}

A convenient sample of five (30\%) staff members from the NABS and TasDeaf were invited to participate in an interview. Among the five staff members, two were Deaf. The remaining three were interpreters for the Deaf. 
As these participants are in close contact with the Deaf community on a regular basis, it was felt that their participation would offer rich contextual information.

\section{Data collection and procedure}

It was felt to be ideal to conduct focus groups with members of the Deaf community, because using focus groups with Deaf participants is consistent with Deaf culture, which often views social gatherings as opportunities for sharing information and can be quite a successful process (Balch \& Mertens, 1999). Confidentiality within the focus group was explicitly highlighted. Participants were only to share information they were comfortable to share with the group and information sharing was to be respected by all participants. It was noted that due to the participants knowing each other, many since childhood, they were all comfortable speaking about their experiences and many knew the stories previously, which has been observed with other focus groups with people who are Deaf (Balch \& Mertens, 1999). Those individuals who were Deaf and unable to participate in a focus group were interviewed individually. Often the reason for participating in an interview was because of distance from other community members or work commitments.

There were nine key questions for Deaf participants that centred on their life story, being Deaf, and their friends and family. In addition, other questions were concerned with what 'health' means; how and where health care is accessed; how the Deaf communicate with health care providers; and what can be done to improve the health of the Deaf community. Similarly, seven key questions were asked from those service providers from TasDeaf. The questions included what current services were being provided by the organisation; what are the general and health needs of the Deaf community and how are they being met; what the main challenges encountered by the Deaf community; and how and in what ways do the Deaf community cope. The interview and focus group questions were adapted from a study conducted among the Deaf community in the United States by Steinberg, et al. (2006). These questions were specifically designed for the Deaf with consideration given to English is a second language and possible English literacy issues.

Each interview or focus group was between 30 and 90 minutes and was audio and/or video recorded with the permission of each participant. An interpreter was present for Deaf participants and those service providers who were also Deaf, to translate questions into Auslan and to relay Deaf participant's discussion into spoken English for the researcher. The interview and focus group data were subsequently transcribed, by one researcher, into a Microsoft Word document and each interviewee was provided with a transcript and invited to edit, change or add information to the transcript as required. All data were coded numerically to ensure confidentiality, however those service providers who were hearing were also coded accordingly.

\section{Data analysis}

The transcribed interview and focus group data were checked against audio recordings for transcribing consistency and imported to NVivo 10 software, which was used to collate and code the data. Data were then analysed with a central focus on social domains with regard to power inequity, inequalities and prejudice. These included but were not limited to: political discourse, ideology, ethnocentrism and gender, economic discourse, media discourse, institutional discourse and education (see Blommaert \& Bulcaen, 2000; Van Dijk, 2001).

Recurring discourses were systematically identified in the data (Braun \& Clarke, 2006; Fereday \& MuirCochrane, 2008). An examination of the vocabulary, grammar and linguistic patterns as well as how discourses were drawn on by each participant or group was conducted. Throughout this process, key phrases and words were identified from the data, which were then placed into corresponding pre-classified or newly identified discourses. Breaking these data groups into smaller groups of data then followed this process. How each discourse was produced, and in which 
context, was then analysed. This involved assembling singular or small words and phrases, which allowed a more comprehensive picture of power and hegemony to emerge (Aronson, 1994; Boyatzis, 1998).

\section{Results}

\section{Misconceptions and the devaluation of the Deaf}

The perception of the Deaf among some families, organisations and the wider community was discussed by a number of the service providers. According to these accounts, the hearing community in Tasmania often do not recognise Deaf culture and can dismiss Deaf language. Participants highlighted how, because of the Deaf's limited perception of oralaural language, very often, the hearing underestimate the intellectual ability of the Deaf and ignore the Deaf's ability to communicate in alternative ways. One service provider shared how:

There seems to be a correlation, with the general population, that if your hearing goes down that your IQ does too. It is huge; they look at a Deaf person and think 'poor little buggers' [but] they could have a university education (Service interview participant 3 - Hearing).

Another service provider defended the Deaf against the popular misconception that deafness signals intellectual ability.

There is nothing wrong with their brain if given access to language acquisition and a means to accessing communication (Service interview participant 2 - Hearing).

These accounts suggest that deafness remains predominately understood as a disability within the broader hearing community (Ladd, 2005; Lane, 2002; McKee, 2008). The Deaf are perceived as 'less-than' or 'lacking' in comparison to the hearing, a perception that constrains the influence of alternative understandings of deafness to gain traction within the broader social world (Ladd, 2005).

The conversations with the Deaf and their service providers indicated that the real needs and experiences of the Deaf are not generally understood by the hearing. In many accounts, the way in which cochlea implants are predominately understood and spoken about within the medical and broader communities embodied this lack of understanding. Cochlea implants are often viewed as the 'solution' to deafness (McKee, 2008) and for the Deaf, this epitomises the way in which deafness itself is popularly perceived; not as a legitimate way of experiencing and being in the world, but as a disease, something that can be 'fixed'. Yet for the Deaf, it 'is not like it [deafness] is a disease' (Interview participant 6) that needs to be fixed. Deaf participants challenged the assumption that all Deaf people necessarily want cochlea implants (Lane, 2002), with some stating, 'I hate [Cochlea implants], I think they are ugly' (Focus group participant 2). Others challenged the perception that cochlea implants 'cure' deafness arguing that cochlea implants 'are good, but you are still a Deaf person' (Interview participant 1).

These sentiments were reverberated among other Deaf participants who expressed exasperation, anger and a sense of loss related to cochlea implants. For example, two participants expressed that children needed to have a choice about cochlea implant surgery.

I would like to see children not being implanted with Cochlea implants until they are 18 so they can make a decision for themselves on what they want; it is not up to the parents to decide. That makes me angry; it is 
frustrating for me, parents think that... they can implant a Cochlea. They just don't realise that they are not going to learn to sign (Interview participant 4).

Children are mostly getting cochlea implants now so they are not signing very much and their mothers and fathers are speaking. That is frustrating (Interview participant 6).

For these participants, Deafness is an identity; it is not a disease that requires treatment. While some service providers expressed that cochlea implants have their place as a piece of technology to assist those who are deaf, particularly 'for hearing people who have lost their hearing' (Service interview participant 2 - Hearing), others argued that:

If you are going to make a decision to have a Cochlea implant on a young child you need to sign as well [...] you can give your child everything available to them (Service interview participant 2 - Hearing).

Some service providers drew on their past experiences within the Deaf community to critique the assumption that cochlea implant surgery during childhood is always the best option. For example, one service provider described how:

I knew three people that had Cochlea implants put in by their parents and as soon as they were 18 years old they threw them away and went and acquired sign language and they are comfortable now (Service interview participant 5 - Hearing).

Another service provider shared their disappointment about the medical fraternity’s understanding of deafness.

A parent went with their deaf child to the specialist. They were talking about cochlea implant versus sign language and he said sign language is passé. Now if we have the medical community saying that to parents it is just wrong. People in the medical industry seem to think the cochlea implant fixes everything and it doesn't (Service interview participant 3 - Hearing).

This statement demonstrates the way in which medical professionals 'continue to pathologize deafness' (Foss, 2014) and how the needs of the Deaf are frequently dismissed within this discourse. Combined, these discussions highlight a disparity between how deafness is popularly understood within the medical and broader community, and what it means for the Deaf. The dominance of deficiency, disability and disease discourses is sustaining these relations, and preventing discourses of Deafhood, independence and self-sufficiency from gaining legitimacy within the wider social field (Lane, 2002; Padden \& Humphries, 2009).

\section{Ignoring the Deaf's communication needs}

In conjunction with the limitations implicit in having only two major interpretive services within the state, participants shared that there was only one full-time position and a number of casual interpreters employed through NABS (Nationally-funded for health related appointments) in the state. Further to this, TasDeaf interpreters had ceased being officially employed by TasDeaf and were all working in a casual capacity. Participants also explained that there are two divisions or levels of interpreters; level two and level three. Level two interpreters deal with general interpreting whereas level three interpreters are those who are (or should be):

Dealing with medical, legal, police [...] within medical you may be telling someone that they are dying of cancer. You shouldn't have a level two who doesn't have that skill set and doesn't work in that industry, explaining the body, organs and what the doctor is going to do. If you get it wrong it is not good for the client (Service interview participant 2 - Hearing). 
Yet despite the need for such experienced interpreters, there were only three level three interpreters in the whole state at the time this study was conducted, one of whom was full-time and all of whom were based in the capital city, which is more than five hours drive to parts of the state where a number of Deaf were living. Exacerbating this challenge is the impracticability of level two interpreters undertaking further training. The training is a lengthy process and offered in a different state of Australia 'which is prohibitive for most people and anyone who goes doesn't come back for a few years' (Service interview participant 2 - Hearing).

Although provisions were often made for those who were Deaf in health care settings, there was usually a sense that equal access was out of reach. For example, one participant stated 'We need equal access to information and services in own language for clear understanding' (Interview participant 3). To this, a service provider stated:

I don't like to see people depending on other people, I like to see people accessing services that they are entitled to and having that independence. (Service interview participant 1 - Deaf)

Interpretative services were considered a priority because the Deaf are a 'linguistic minority' (Service interview participant 2 - Hearing), often have low English literacy, and involving family or other informal interpreters compromises privacy (Denman, 2007). Yet a lack of interpreters meant that 'people come and say they can't access interpreters and so they take their families' (Service interview participant 4 - Deaf).

Some Deaf people did not involve family in interpretation due to the private nature of their health needs. It was also felt to be problematic because family tend to lack the requisite skills to interpret for many key organisations, such as legal and medical services. Nevertheless, it was indicated that family can be viewed as a suitable alternative to trained interpreters.

They often have their family members to come with them [...] and often the children have to interpret for the parents and that is really dangerous as they could be giving the wrong information (Service interview participant 2 - Hearing).

Family and friends are doing their best to help, but I would rather see people using interpretive services and organisations being held accountable (Service interview participant 4 - Deaf).

In some instances, the Deaf indicated that they use family for simple appointments or, importantly, when they are unable to access interpretive services (Denman, 2007). Some Deaf participants also expressed fears about being a burden to their children or hesitation in revealing a private matter to other family members. When family were used, it often fell upon a mother or daughter to provide interpreting. In many cases, this choice was based on the limited communication skills that other members of the family had with the Deaf individual.

Members of the Deaf community shared different experiences of health service's responses to their communicative needs. Some of these experienced included:

I book an interpreter and go to the doctor. That is really important as it is so hard if you have to write English [to communicate]. With an interpreter it is so much easier for me and it is the best thing and my doctor is happy to have an interpreter (Focus group participant 9).

When seeing the GP or the specialist... we will ask for an interpreter and I get them to book it, but the doctor would say it is not their job. I tell them it is your job. You are asking me to come and you must organise an interpreter. I have had to be cruel to get them to do that (Focus group participant 7).

I will say it is my right to have access to an interpreter and I need to have an interpreter... It is really important to have interpreting service. I will insist on that (Interview participant 1). 
Educating services about their responsibility to book an interpreter was something that many Deaf people felt was their responsibility to enforce in order to ensure they had equitable access to health services.

In this context, service provider participants discussed some of the discriminatory practices their clients report experiencing in health care settings. For example, health-related interpreting costs are covered through the NABS; however, 'interpreting is traditionally been government funded fee for service, but there is a lot of interpreting that isn't government funded that is very necessary' (Service interview participant 2 - Hearing). It was highlighted that 'sometimes the interpreter can't make it to the appointment and sometimes service don't want to pay for it as they don't or can't get funding for interpreters' (Service interview participant 1 - Deaf).

In addition to the cost of accessing services, some of the Deaf choose not to access any of the interpretive services available. One participant explained:

I don't want [the service provider for the Deaf] to think that I am poor and deaf and that I need help. No, I am strong, I stand up and I can do it myself [...] I have my own way. (Interview participant 3)

It was later revealed that the frustration and annoyance was with the situation that the Deaf were faced with in terms of equal access as 'hearing people can go straight away and have access to services' (Interview participant 11).

\section{Devaluation and disrespect within the family}

Communication within the family was an important topic raised by all Deaf participants. Some of the Deaf participants expressed pride and happiness in the communication they had, particularly with their hearing children and grandchildren. However, there were some who shared sadness that a parent or sibling/s did not communicate well with them. In one instance, a participant stated:

I don't have any deaf family; it is only myself my whole life. It is very difficult to communicate with my parents, sisters and brothers. None of them learned sign language. I only talked with my mum, but she only knows a little bit (Interview participant 10).

In addition to poor communication with family members, it was also reported that family can talk around the individual as if they were not in the room, or may make decisions for the Deaf family member without consulting them. In one instance, a service provider stated that parents had told their Deaf child not to use sign language or make vocal noises when in public. This has had a lifelong impact particularly when:

You have an intelligent human being what just happens to be deaf and they are treated as a second class citizen in their own family (Service interview participant 4 - Deaf).

Some comments were also made around missing a lot of the family conversation and when the Deaf person asks what is being discussed, the request would usually be dismissed. In many instances, there were large areas of the Deaf individual's life that were missing, such as family stories, family history and medical histories. One Deaf person shared an experience when they were younger. They used to frequently visit with an old lady and she looked after them on a regular basis, but it was not until this individual was an adult and the old lady had passed away that they were told it was their grandmother. Similar stories were shared by other Deaf participants about meeting relatives but not knowing who they were until much later in their lives. 
In addition to missing out on family stories and knowing who people were, it was also highlighted that Deaf people can grow up with limited access to general public information and conversations. A service provider participant explained that:

Deaf people miss out on a lot of information such as general conversation, television or radio... They may not be getting the information unless they are literate enough to read it in the paper, in magazines and websites (Service interview participant 2 - Hearing).

Overall, it was felt that those who are hearing are advantaged because they are more aware, at a younger age, about the world around them and the challenges they may encounter.

\section{The Deaf's strategies in facing challenges}

Taking into account some of the common life experiences of the Deaf, service providers emphasised that, within the Deaf community, there can be a lack of confidence that impacts access to services or information. However, the Deaf were more resilient than could be expected and had developed many of the skills to manage and cope within the wider community. This was pointed out when one participant explained:

I try to write and communicate more with hearing people, it lifts me up when I communicate with both Deaf and hearing people [...] why should I be ashamed or embarrassed. I have learned to stand up on my own (Interview participant 3).

Another participant emphasized that they needed to develop their own confidence:

I had to develop my own confidence. I was the only deaf person at [high school] at that time and so I had to develop that confidence myself and I had to build it up. I had to open up to have many hearing friends (Interview participant 2).

This view was in contrast to some of the older Deaf participants who had a more difficult time at school. However, these participants also developed resilience and skills to cope in the wider community. Some accounts amongst these older participants included:

I never learned much, no one taught me about life. I have had a lot of trouble and have done a lot of things wrong, but when I became older I improved myself. (Interview participant 5)

When I was young, I didn't learn much, but I learned ways to cope when growing up, but I didn't learn at home through conversation (Interview participant 6).

It was found that the Deaf's resilience had been developed throughout their lives. In some cases, developing coping strategies was not out of choice but in response to the lack of interpretive services, which caused frustration. In response to these challenges, the Deaf learned requisite skills to manage and function within a community of hearing people.

\section{Conclusion}

What is and is not considered a disability is determined by the technologies of normalisation operating within a given space-time; the socially constructed meanings assigned to life experiences (Lane, 2002). According to Lane 
(2002), audism is a form of discrimination on par with racism and sexism. It is based on the belief that 'inherent biological factors determine individual traits and capacity' (Lane, 2002, p. 364). Lane (2002) argues that the constraints the Deaf experience during their lives are largely the result of audist discourses, and the way they construct deafness.

Our conversations with members of the Deaf community and their service providers indicated that the audist discourses of deafness as deficiency, disability and disease remain dominant in contemporary Tasmanian society, despite their inconsistency with the Deaf's own perception of their reality. While Deafhood is a dynamic process of identity formation for those who experience it, in the hearing world, deafness is portrayed as a disabling trait, and it used to dehumanise (Lane, 2002); where dehumanisation is an expression of personally mediated intolerance or 'differential assumptions about the abilities, motives, and intentions of others... [which] manifest as lack of respect, suspicion, devaluation' (Jones, 2000, p. 121).

The Deaf participants in this study were pushing back on discourses that construct deafness as an disempowering impairment, illustrated in language like 'it is not up to the parents to decide', 'I don't want [the service provider] to think I am poor and deaf and that I need help', 'I have learned to stand up on my own' and 'it is my right to have access to an interpreter.' As mostly hearing participants, the service providers who participated in this study were also challenging popular misconceptions about the Deaf; much of their language was positive in its delivery and expression. However, these participants were able to articulate the dominant ways in which the Deaf are perceived within the medical and broader communities. This was encapsulated in descriptions of the Deaf as 'second class citizen', 'sign language is passé', 'poor little buggers' and 'if your hearing goes down [...] your IQ does too.' This language reveals the type of contemporary prejudice the Deaf frequently encounter in health settings.

Despite the dominant constructions of deafness and their affect on the Deaf's experience of health service provision, it was found that many Deaf have developed skills, confidence and resilience to live and access health care in the hearing world. They are not to be pitied. It is the society around them that has 'disabled' the Deaf (Oliver, 1990). In this study, the Deaf were advocating for choice around cochlea implant surgery. The Deaf emphasised the loss that is associated, not with deafness, but with receiving a cochlea implant; a loss of language and identity, which is threatening Deaf culture (Foss, 2014). Contrary to dominant constructions, 'being able to hear is not as important as being a member of the deaf community' (McDermott \& Varenne, 1995, p. 329).

The Deaf community's need for greater self-determination and independence is situated within a broader culture where sound, speech and the language of the hearing is dominant (Van Dijk, 2003). This dominance is a form of social power that exercises control over others, resulting in social inequality. In most cases, it is in the self-interests of the hearing that control over others is exerted (Van Dijk, 1996). Even if the Deaf conform to the social conventions, rules and standards of hearing culture, social power and authority is still implicitly exerted over them. In many cases, the assumptions regarding the ability and capacity of the Deaf are unfounded; based on social stereotyping rather than actual ability (Foss, 2014; Padden \& Humphries, 2009; Van Dijk, 2003). Yet these dominant assumptions about the Deaf have the potential to be constantly re-enforced through discourse, which influences the power relationships between the Deaf and the hearing.

\section{Limitation}

The study was limited due to low participation rates from the Deaf community which has an overall impact on the generalizablility of the findings, nevertheless the study provides insight into a number of challenges that smaller isolated Deaf communities may encounter when compared to larger Deaf populations. 


\section{Conclusion}

Dominant discourses and the stereotypes they create continue to portray deafness as a deficiency, disability and/or disease, and the Deaf as intellectually inferior, unintelligent, and incompetent. This study has examined, through the voices of the Deaf and supported by some of their service providers, the issues and challenges they encounter living within the hearing world and particularly when accessing health care. This examination has illustrated how the challenges the Deaf in Tasmania encounter are underpinned by the dominant portrayal of the Deaf. Despite the barriers they encounter, the Deaf in this study were resilient; they had developed skills and confidence to live within the hearing world. Nevertheless, those who are hearing, such as family and medical personnel, continue to be indifferent to and dismissive of the needs of the Deaf. This is subjugating the Deaf; undermining their independence and self-sufficiency in ways that continue to reproduce social and health inequity and inequality.

\section{References}

Alvesson, M., \& Karreman, D. (2000). Varieties of discourse: On the study of organizations through discourse analysis. Human Relations, 53(9), 1125-1149.

Aronson, J. (1994). A pragmatic view of thematic analysis. The qualitative report, 2(1), 1-3.

Australian Bureau of Statistics. (2012, 2 November 2011). National Regional Profile 2006-2010.from http://www.ausstats.abs.gov.au/ausstats/nrpmaps.nsf/NEW+GmapPages/national+regional+profile?opendocument

Balch, G. I., \& Mertens, D. M. (1999). Focus group design and group dynamics: Lessons from deaf and hard of hearing participants. American Journal of Evaluation, 20(2), 265-277.

Barnett, S., Klein, J. D., Q Jr, P. R., Samar, V., Schlehofer, D., Starr, M., . . Pearson, T. A. (2011). Community participatory research with deaf sign language users to identify health inequities. American Journal of Public Health, 101(12).

Batterbury, S. C. E., Ladd, P., \& Gulliver, M. (2007). Sign Language Peoples as Indigenous Minorities: Implications for Research Policy. Environment and Planning A, 39(12), 2899-2915. doi: http://www.envplan.com/epa/epa current.html

Blommaert, J., \& Bulcaen, C. (2000). Critical Discourse Analysis. Annual review of Anthropology, 29, 447-466.

Bodenheimer, T., Chen, E., \& Bennett, H. D. (2009). Confronting the growing burden of chronic disease: can the US health care workforce do the job? Health affairs, 28(1), 64-74.

Boyatzis, R. E. (1998). Transforming qualitative information: Thematic analysis and code development: Sage Publications.

Braun, V., \& Clarke, V. (2006). Using thematic analysis in psychology. Qualitative Research in Psychology, 3(2), 77101.

Davidson, F., Cave, M., Reedman, R., Briffa, D., \& Dark, F. (2012). Dialectical behavioral therapy informed treatment with Deaf mental health consumers: an Australian pilot program. Australasian Psychiatry, 20(5), 425-428.

Deaf Australia Inc. (2014). Deaf Australia Inc., 31 January, from www.deafau.org.au

Denman, L. (2007). Enhancing the accessibility of public mental health services in Queensland to meet the needs of deaf people from an Indigenous Australian or culturally and linguistically diverse background. Australasian Psychiatry, 15, S85-S89. doi: 10.1080/10398560701701262 
Department of Health. (2005). Mental Health and Deafness: Towards Equity and Access (pp. 36). Londonthe National Institute for Mental Health in England.

Dunmire, P. L. (2011). Projecting the future through political discourse (Vol. 41). Amsterdam: John Benjamin Publishing Co.

Fairclough, N. (1992). Discourse and social change. Cambridge, UK: Polity Press.

Fairclough, N., \& Wodak, R. (1997). Critical Discourse Analysis. In T. A. Van Dijk (Ed.), Discourse as social interaction (pp. 258-284). London: Sage.

Fereday, J., \& Muir-Cochrane, E. (2008). Demonstrating rigor using thematic analysis: A hybrid approach of inductive and deductive coding and theme development. International Journal of Qualitative Methods, 5(1), 80-92.

Foss, K. A. (2014). Constructing Hearing Loss or "Deaf Gain?" Voice, Agency, and Identity in Television's Representations of d/Deafness. Critical Studies in Media Communication, 31(5), 426-447. doi: $10.1080 / 15295036.2014 .968603$

Graybill, P., Aggas, J., Dean, R. K., Demers, S., Finigan, E. G., \& Pollard, R. (2010). A Community-Participatory Approach to Adapting Survey Items for Deaf Individuals and American Sign Language. Field Methods, 22(4), 429448. doi: $10.1177 / 1525822 \times 10379201$

Harmer, L. (1999). Health care delivery and deaf people: practice, problems, and recommendations for change. Journal of deaf studies and deaf education, 4(2), 73-110.

Hyde, M., \& Power, D. (1992). The Use of Australian Sign Language by Deaf People. Sign Language Studies, 75, $167-182$.

Johnston, T. (2004). W(h)ither the Deaf community? Population, genetics and the future of Australian Sign Language. American Annals of the Deaf, 148(5), 358-375.

Jones, C. P. (2000). Levels of racism: a theoretic framework and a gardener's tale. American Journal of Public Health, 90(8), 1212-1215. doi: 10.2105/ajph.90.8.1212

Ladd, P. (2005). Deafhood: a concept stressing possibilities, not deficits. Scandinavian Journal of Public Health, 33(Suppl 66), 12-17.

Ladd, P., \& Lane, H. L. (2013). Deaf Ethnicity, Deafhood, and Their Relationship. Sign Language Studies, 13(4), 565-579.

Lane, H. L. (2002). Do Deaf People Have a Disability? Sign Language Studies, 2(4), 356-379.

McCloskey, R. (2008). A guide to discourse analysis. Nurse researcher, 16(1), 24.

McDermott, R., \& Varenne, H. (1995). Culture as disability. Anthropology \& Education Quarterly, 26(3), 324-348.

McKee, R. L. (2008). The Construction of Deaf Children as Marginal Bilinguals in the Mainstream. International Journal of Bilingual Education and Bilingualism, 11(5), 519-540.

Moore, J. D., \& Pollack, M. E. (1992). A problem for RST: The need for multi-level discourse analysis. Computational linguistics, 18(4), 537-544.

Napier, J., \& Kidd, M. R. (2013). English literacy as a barrier to health care information for deaf people who use Auslan. Australian Family Physician, 42(12), 896-899. 
Nilsson, A., Turner, G., Sheikh, H., \& Dean, R. (2013). A prescription for change: report on EU healthcare provision for Deaf sign language users. from http://www.medisignsproject.eu/download/report.pdf

Oliver, M. (1990). The politics of disablement. London: Macmillan Education.

Padden, C., \& Humphries, T. (2009). Inside deaf culture. Boston, MA: Harvard University Press.

Sheppard, K., \& Badger, T. (2010). The lived experience of depression among culturally Deaf adults. Journal of psychiatric and mental health nursing, 17(9), 783-789. doi: 10.1111/j.1365-2850.2010.01606.x

Steinberg, A. G., Barnett, S., Meador, H. E., Wiggins, E. A., \& Zazove, P. (2006). Health care system accessibility. Journal of general internal medicine, 21(3), 260-266.

Steinberg, A. G., Sullivan, V. J., \& Loew, R. C. (1998). Cultural and linguistic barriers to mental health service access: the deaf consumer's perspective. American Journal of Psychiatry, 155(7), 982-984.

Van Dijk, T. A. (1996). Discourse, power and access. In C. R. Caldas-Coulthard \& M. Coulthard (Eds.), Texts and practices: Readings in Critical Discourse Analysis (pp. 84-104). London: Routledge.

Van Dijk, T. A. (2001). Critical Discourse Analysis. In D. Schiffrin, D. Tannen \& H. E. Hamilton (Eds.), The handbook of discourse analysis (pp. 352-371). Oxford: Blackwell Publishing.

Van Dijk, T. A. (2003). The Discourse-Knowledge Interface. In G. Weiss \& R. Wodak (Eds.), Critical Discourse Dnalysis: Theory and interdisciplinarity (pp. 85-109). New York: Palgrave Macmillan.

Wodak, R. (2002). Aspects of Critical Discourse Analysis. Zeitschrift für Angewandte Linguistik, 36, 5-31.

Wodak, R., \& Meyer, M. (2009). Critical Discourse Analysis: Hisotry, agenda, theory and methodology. In R. Wodak \& M. Meyer (Eds.), Methods of critical discourse analysis (2nd ed., pp. 1-33). London: Sage Publications. 